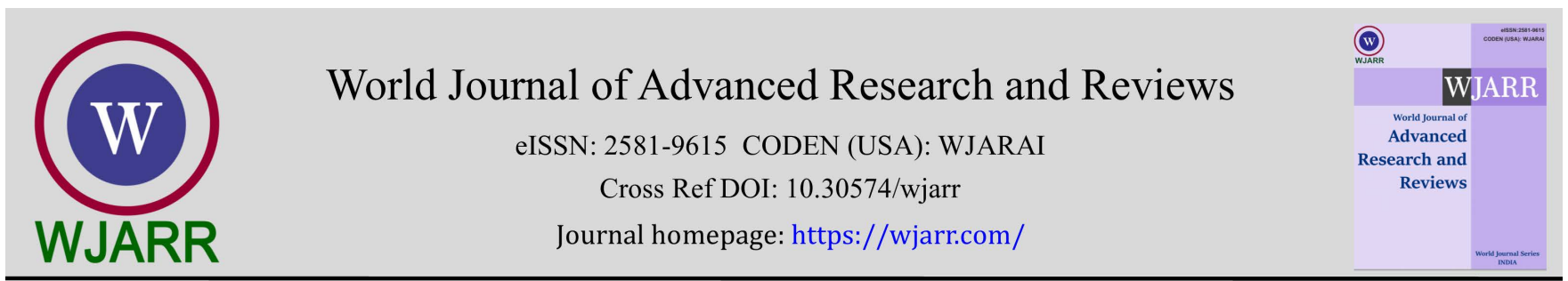

(RESEARCh ARTICLE)

\title{
Changes in the frequency of eating out, consuming ready-to-eat meals, and eating at home before and after the spread of COVID-19 among students
}

\author{
Tatsuya Koyama * and Shin Yamaoka \\ Department of Nutrition, Faculty of Health Sciences, Aomori University of Health and Welfare.
}

World Journal of Advanced Research and Reviews, 2022, 13(02), 136-141

Publication history: Received on 05 January 2022; revised on 06 February 2022; accepted on 08 February 2022

Article DOI: https://doi.org/10.30574/wjarr.2022.13.2.0133

\begin{abstract}
This study aimed to examine changes in the frequency of eating out before and after the coronavirus disease (COVID19) pandemic. In January 2021, a self-administered questionnaire survey was conducted among 21 third-year students in Aomori City, Japan. Participants completed the survey containing questions on their characteristics, monthly food expenses, changes in meals between January 2020 and January 2021, frequency of eating out in January 2020, frequency of purchases of ready-to-eat products in January 2020, current reasons for eating out, current reasons for refraining from eating out, and situations where they would not refrain from eating out in the future. In 2020, nine people (43\%) answered "once a week" as the frequency of eating out. The change in the frequency of eating out and the change in the frequency of ready-to-eat meal showed a positive correlation $(r=0.796)$, while the frequency of eating out and the frequency of consuming home meals showed a negative correlation ( $r=-0.661)$. It was suggested that the frequency of eating out may be negatively associated with the frequency of consuming home-cooked meals among students.
\end{abstract}

Keywords: Coronavirus infection; Frequency of eating out; Frequency of ready-to-eat meals; Frequency of home meals; Students

\section{Introduction}

Cases of individuals suffering from an acute respiratory illness were reported in Wuhan, China in December 2019, after which the disease was determined to be a new type of coronavirus. The infection spread to Asia, Europe, and North America, and on March 11, 2020, the World Health Organization declared the outbreak of the severe acute respiratory syndrome coronavirus 2 (SARS-CoV-2) as a pandemic. The first infected person in Japan was confirmed on January 16, 2020. Subsequently, the number of infected people gradually increased. The first infected person was confirmed in Aomori Prefecture on March 23, and the first infected person was confirmed in Aomori City on April 3. On April 7, a state of emergency was issued to seven prefectures, mainly in the Tokyo metropolitan area and the Kansai area, and on April 16, the state of emergency was expanded to all prefectures. Thereafter, the state of emergency was lifted in 39 prefectures on May 14, lifted in the three Kansai prefectures on May 21, and completely lifted on May 25. There were no inpatients infected with COVID-19 in Aomori Prefecture by June 1, but infected people were confirmed once more in Aomori Prefecture for the first time in 63 days on July 9 (Aomori City), and infections continued to spread in Aomori City.

Amid the rising COVID-19 infections, the frequency of eating out decreased, owing to the issuance of the state of emergency as well as lifestyle changes. According to a survey by the Food Service Association, sales from individuals eating out has decreased significantly compared to before the spread of COVID-19 [1]. However, research on changes in eating behavior before and after the spread of coronavirus infection in Japan is limited.

\footnotetext{
* Corresponding author: Tatsuya Koyama

Department of Nutrition, Faculty of Health Sciences, Aomori University of Health and Welfare.

Copyright $(2022$ Author(s) retain the copyright of this article. This article is published under the terms of the Creative Commons Attribution Liscense 4.0.
} 
Therefore, we focused on the reasons for students choosing to eat out or refraining from doing so. The study was conducted among students of a university in Aomori City, focusing on changes in the frequency of eating out before and after the spread of COVID-19.

\section{Method}

In January 2021, a questionnaire survey was conducted among 36 third-year students from a university in Aomori City. The questions were on participants' characteristics (gender, living style), monthly food expenses, frequency of eating out in that month, frequency of eating out in January 2020, reason for currently eating out, reason for currently refraining from eating out, and a situation in which the individual would not refrain from eating out.

The questionnaire assessed the participants' food expenses (the total amount you ate or drank in the past month, and the amount you spent). Participants could respond as follows: 0 to less than 10,000 yen, 10,000 to less than 20,000 yen, 20,000 to less than 30,000 yen, 30,000 to less than 40,000 yen, 40,000 to less than 50,000 yen, and 50,000 yen or more. Questions assessed the frequency of eating out and frequency consumption of ready-to-eat products in January 2020; details on how much they ate out (excluding eating during part-time jobs and from the student cafeteria) and how many ready-to-eat products they consumed (e.g., take-out lunch boxes, hamburgers, and side dishes) in January 2020 was also sought [2]. Participants could respond as follows: twice a day or more, once a day, 4-6 times a week, 2-3 times a week, once a week, less than once a week, none. Changes in meal consumption between January 2020 and January 2021 included home-cooked meals (cooked by yourself or your family), ready-to-eat products (e.g., take-out lunch boxes and hamburgers) and eating out (excluding eating at part-time jobs and in the student cafeteria). Participants could respond as follows: decreased, slightly decreased, no change, slightly increased, and increased, for each meal type. We also posed a question to assess participants' reasons for currently eating out (why you are currently eating out). Participants could respond as follows: because the emergency declaration has been lifted in Aomori Prefecture, because Aomori Prefecture has lifted the request to refrain from travelling and to from close stores, because the number of newly infected people is decreasing and the risk of infection is considered to be low, stores are fully prepared with infection prevention measures, because you were invited by people around you, because the request for self-restraint from the university has been lifted, because you are not infected and you are confident that you will not infect other people, even if infected, it is considered that the treatment method is almost established, there is no particular reason, and you do not eat out. We asked the reason for participants refraining from eating out currently as follows: "Why have you currently refrained from eating out?" Participants could respond as follows: because the risk of infection is still considered high despite the number of newly infected people decreasing, because no silver bullet or vaccine for the new coronavirus has been developed, because you may infect other people if you are asymptomatic, because the declaration of emergency has been issued in other areas, because you feel that it is better to refrain from public trends, because infection control measures in stores are not sufficient, because it is difficult to invite people around you, I don't know if I can invite others, there is no particular reason, and you don't refrain from eating out. For "situations where you will not refrain from eating out in the future," ask "what kind of situation will you restart to eat out?"

The results are presented as numbers and percentages. We examined the correlation between changes in meal content (home meals, prepared meals, eating out, eating at part-time jobs, and in the student cafeteria) between January 2020 and January 2021. That is, for each meal type, "decreased" was scored as -2, "slightly decreased" as - 1 , "unchanged" as 0 , "slightly increased" as +1 and "increased" as +2 . The Spearman correlation coefficient was calculated using SPSS 26.0 (v26, IBM Japan Inc.), and the significance level was set at $5 \%$.

\section{Results}

Twenty-one participants responded to the questionnaire (response rate: 58\%). Respondents consisted of 3 males (14\%) and 18 females (86\%); one participant (5\%) lived with her family, and 20 lived alone (95\%). Fourteen respondents answered that food cost was 10,000 to less than 20,000 yen, (67\%), 5 respondents $(24 \%)$ answered 20,000 to 30,000 yen, and 2 respondents (10\%) answered 30,000 to 40,000 yen.

In January 2020, the frequency of eating out was once a day for 1 person (5\%), 2 to 3 times a week for 2 people (10\%), once a week for 9 people (43\%), less than once a week for 8 people (38\%), and none for 1 person (5\%). In January 2020, the frequency of consumption of ready-to-eat products was twice or more daily for two people (10\%), once daily for 1 person (5\%), 4 to 6 times a week for 3 people (14\%), 2 to 3 times a week for 6 people (29\%), once a week for 8 people $(38 \%)$, and less than once a week for 1 person (5\%). 
Table 1 shows the changes in meal types between January 2020 and January 2021. With regards to home-cooked meals, 4 people (19\%) answered "decreased" or "slightly decreased," and 9 people (43\%) answered "no change," while 8 people (38\%) answered "increased" or "slightly increased." With regards to ready-to-eat products, 1 person (5\%) answered "decreased" or "slightly decreased," 7 people (33\%) answered "no change," and "increased" or "slightly increased" were selected by 13 people (62\%). With regards to eating out, 9 people (43\%) answered "decreased" or "slightly decreased," 8 people (38\%) answered "no change," and 4 people (19\%) answered "increased" or "slightly increased." With regards to eating at part-time jobs, 7 people (33\%) answered "decreased" or "slightly decreased," 13 people (33\%) answered "no change," and 1 person (5\%) answered "increased" or "slightly increased." With regards to consumption in the cafeteria, 16 people (76\%) answered "decreased" or "slightly decreased," 5 people (24\%) answered "no change," and none answered "increased" or "slightly increased."

Table 1 Changes in dietary content between January 2020 and January $2021(n=21)$

\begin{tabular}{|l|c|c|c|c|c|c|c|c|c|c|}
\hline & \multicolumn{2}{|c|}{ Decreased } & \multicolumn{2}{c|}{$\begin{array}{c}\text { Slightly } \\
\text { reduced }\end{array}$} & \multicolumn{2}{c|}{$\begin{array}{c}\text { did not } \\
\text { change }\end{array}$} & \multicolumn{2}{c|}{$\begin{array}{c}\text { Slightly } \\
\text { increased }\end{array}$} & \multicolumn{2}{c|}{ Increased } \\
\hline & $\mathrm{n}$ & $\%$ & $\mathrm{n}$ & $\%$ & $\mathrm{n}$ & $\%$ & $\mathrm{n}$ & $\%$ & $\mathrm{n}$ & $\%$ \\
\hline Home meal & 0 & $0 \%$ & 4 & $19 \%$ & 9 & $43 \%$ & 6 & $29 \%$ & 2 & $10 \%$ \\
\hline Ready-to-eat meal & 1 & $5 \%$ & 0 & $0 \%$ & 7 & $33 \%$ & 12 & $57 \%$ & 1 & $5 \%$ \\
\hline Eating out & 5 & $24 \%$ & 4 & $19 \%$ & 8 & $38 \%$ & 3 & $14 \%$ & 1 & $5 \%$ \\
\hline Eating at part-time job & 5 & $24 \%$ & 2 & $10 \%$ & 13 & $62 \%$ & 1 & $5 \%$ & 0 & $0 \%$ \\
\hline Student cafeteria & 7 & $33 \%$ & 9 & $43 \%$ & 5 & $24 \%$ & 0 & $0 \%$ & 0 & $0 \%$ \\
\hline
\end{tabular}

Table 2 shows the correlation between changes in consumption frequency between January 2020 and January 2021. Changes in the frequency of consumption of home meals and that of ready-to-eat products ( $\mathrm{r}=-0.609)$, and changes in the frequency of consumption of home meals and that of eating out ( $\mathrm{r}=-0.661)$, were negatively correlated; a positive correlation was found between changes in the frequency of eating out and changes in the frequency of prepared meals $(r=0.796)$.

Table 2 Correlation of changes in consumption frequency between January 2020 and January $2021(n=21)$

\begin{tabular}{|l|c|c|c|c|}
\hline & Home meal & Ready-to-eat meal & Eating out & Eating at part-time job \\
\hline Ready-to-eat meal & $-0.609^{* *}$ & & & \\
\hline Eating out & $-0.661^{* *}$ & $0.796^{* *}$ & & \\
\hline Eating at part-time job & -0.223 & 0.058 & -0.052 & \\
\hline Student cafeteria & -0.163 & 0.125 & 0.409 & 0.181 \\
\hline
\end{tabular}

Table 3 lists the reasons for eating out at present. The most common reason for eating out was "because I was invited by people around me," followed by "because the state of emergency has been lifted in Aomori Prefecture," "Aomori Prefecture has lifted the request to refrain from moving and to close stores," and "there is no particular reason."

Table 3 Reasons for eating out at present (multiple answers allowed) (n=21)

\begin{tabular}{|l|c|c|}
\hline & n & \% \\
\hline Because the state of emergency has been lifted in Aomori Prefecture & 5 & $24 \%$ \\
\hline Aomori Prefecture has been refrained from moving and requests for store closures have been lifted. & 5 & $24 \%$ \\
\hline The number of newly infected people is decreasing, and the risk of infection is considered to be low. & 0 & $0 \%$ \\
\hline Because it is thought that the store's infection control measures are in place. & 2 & $10 \%$ \\
\hline
\end{tabular}




\begin{tabular}{|c|c|c|}
\hline Because I was invited by the people around me & 12 & $57 \%$ \\
\hline Because the request for self-restraint from the university has been lifted & 1 & $5 \%$ \\
\hline Because I'm not infected and I'm confident that I won't infect others & 1 & $5 \%$ \\
\hline Even if infected, treatment is considered to be almost established. & 0 & $0 \%$ \\
\hline There no particular reason & 5 & $24 \%$ \\
\hline Do not eat out & 4 & $19 \%$ \\
\hline
\end{tabular}

Table 4 shows the reasons for refraining from eating out at present. The most common reason for refraining from eating out was "because I feel that it is better to refrain from eating out," followed by "the number of newly infected people is decreasing, but total infections are still considered to be high."

Table 4 Reasons for refraining from eating out (multiple answers allowed) $(n=21)$

\begin{tabular}{|c|c|c|}
\hline & $\mathbf{n}$ & $\%$ \\
\hline $\begin{array}{l}\text { Although the number of newly infected people is decreasing, the risk of infection is still } \\
\text { considered to be high. }\end{array}$ & 10 & $48 \%$ \\
\hline Because no silver bullet or vaccine has been developed & 3 & $14 \%$ \\
\hline If you are asymptomatic, you may infect others. & 9 & $43 \%$ \\
\hline Because the state of emergency has been issued in other areas & 5 & $24 \%$ \\
\hline Because I feel that it is better to refrain from global trends & 13 & $82 \%$ \\
\hline Because I don't think the store's infection control measures are sufficient & 2 & $10 \%$ \\
\hline It's hard to invite people around me, because I don't know if I can invite them & 4 & $19 \%$ \\
\hline There is no particular reason & 2 & $10 \%$ \\
\hline Do not refrain from eating out & 4 & $19 \%$ \\
\hline
\end{tabular}

Table 5 shows the situations in which participants would not refrain from eating out in the future. The most common answer for resuming eating out was "when the epidemic of large-scale infectious diseases disappears and the number of newly infected people nationwide decreases significantly", followed by "when self-restraint fatigue / self-restraint stress increases."

Table 5 Situations where you will not refrain from eating out in the future (multiple answers allowed) (n=21)

\begin{tabular}{|c|c|c|}
\hline & $\mathbf{n}$ & $\%$ \\
\hline When the state of emergency is lifted & 4 & $19 \%$ \\
\hline If the Governor of Aomori lifts the self-restraint from going out & 2 & $10 \%$ \\
\hline $\begin{array}{l}\text { If the epidemic of large-scale infectious diseases disappears and the number of newly infected } \\
\text { people nationwide decreases significantly }\end{array}$ & 15 & $71 \%$ \\
\hline If the number of newly infected people in the municipality where you live starts to decrease & 2 & $10 \%$ \\
\hline $\begin{array}{l}\text { If the frequency of small local outbreaks (clusters) declines and the number of new infections } \\
\text { in the country begins to decline }\end{array}$ & 5 & $24 \%$ \\
\hline If the number of newly infected people in Aomori Prefecture starts to decrease & 4 & $19 \%$ \\
\hline If self-restraint fatigue / self-restraint stress increases & 7 & $33 \%$ \\
\hline
\end{tabular}




\section{Discussion}

For students in Aomori City, we investigated the changes in the types of meals they consumed in January 2020, before COVID-19 spread nationwide, and in January 2021, by which time it had spread throughout the country. About $40 \%$ of respondents answered that their frequency of eating out did not change, and about $40 \%$ decreased or slightly decreased how often they ate out. In a study of students nationwide in July 2020, 36\% answered that they ate out less often, 33\% said they cooked more often than before March 2020, and 43\% of the respondents answered that there was no change [3]. Although the survey period and question content were different from this survey, the results were similar.

About $40 \%$ of the subjects did not change the frequency of eating out before and after the spread of COVID-19 nationwide. There are several possible reasons for this finding. First, Aomori Prefecture had a smaller number of people infected with COVID-19 than the national average, and the duration of the state of emergency was limited to April 16 to May 14, 2020. Therefore, the spread of COVID-19 may have had little effect on behaviors such as eating out.

In addition, about $80 \%$ of students answered that they ate out once a week or less than once a week in January 2020 before COVID-19 spread nationwide. Therefore, the subjects of this survey were originally people who did not eat out often, and hence, it may explain why a greater degree of changes were not observed.

About $30 \%$ of students answered that the frequency of their meals at part-time job would not change. For that reason, the implementation status of part-time jobs by students has not changed significantly before and after the spread of the new coronavirus infection nationwide, and the eating behavior, including the dietary content, has changed significantly.

The results show a negative correlation between changes in the frequency of eating out and that of consuming homecooked meals; that is, those who answered that the frequency of eating out decreased tended to say that the frequency of using home-cooked meals increased. On the other hand, there was a positive correlation between changes in the frequency of eating out and the frequency of processed foods, that is, those who answered that the frequency of eating out decreased tended to say that the frequency of eating out also decreased. Therefore, students who used eating out less frequently became home-cooked meals rather than eating processed foods instead of eating out. It has been reported that after the spread of COVID-19, the trend of eating out has decreased, and the frequency of eating at home and cooking has increased [4]. Whether it is possible to generalize the frequency of consuming home-cooked meals instead of prepared meals as being the reason for the decline in the frequency of using food service requires further studies that specifically target participants who frequently eat out.

Currently, the most common reason for eating out is "because of being invited by people around me," and the most common reason for refraining from eating out is "because I feel that it is better to refrain from eating out." This may suggest that the situation of those around us may have more influence on whether we choose to eat out, compared to a request from the national or prefectural government.

This study had some limitations. The number of participants was 21, which may not be sufficient, and the survey was limited to a single area. In addition, since the participants were students of a registered dietitian training school, it is unclear the extent to which the results of this survey can be generalized. Furthermore, since the target was students, changes in dietary content between January 2020 and January 2021 cannot be regarded as the only changes they experienced before and after the spread of COVID-19. In other words, because the grades of schooling assessed were different, it is possible that schoolwork and the number of courses taken may have been different, which may have affected their meal consumption behaviors between January 2020 and January 2021. The students who participated in this survey were away from the university from the end of April to the beginning of May 2020, but other than that, regular face-to-face classes were held.

\section{Conclusion}

Changes in dietary content (home meals, prepared meals, eating out, eating out, eating in the student cafeteria) in January 2020 before the spread of COVID-19, and after its spread in January 2021, were assessed in a self-administered questionnaire survey answered by 21 students in Aomori City. The study found that those who reported that the tendency of eating out had decreased also tended to report that their consumption of prepared meals decreased, while the tendency of consuming home-cooked meals increased. 


\section{Compliance with ethical standards}

\section{Acknowledgments}

We would like to express our gratitude to everyone who responded to the questionnaire.

Disclosure of conflict of interest

The authors declare no conflict of interest.

\section{Statement of informed consent}

Informed consent was obtained from all individual participants included in the study.

\section{References}

[1] Japan Food Service Association, 2021, Food Service Industry Market Trend Survey by Member Companies of Japan Food Service Association February 2021 Results Report.

[2] Ministry of Health, Labor, and Welfare, National Health and Nutrition Survey in Japan. 2017.

[3] M Hojo, M Toshiro, M Toyama, H Nakazato, M Furukawa, N Shirokoshi, K Shimomura, M Moriwaki, K N Ishihara. Subjective happiness of university Students under the COVID-19 pandemic. Kyoto University Higher Education Research. 26: 41-50

[4] Hayashi, Fumi, Yukari Takemi. Factors Influencing Changes in Food Preparation during the COVID-19 Pandemic and Associations with Food Intake among Japanese Adults. Nutrients. 2021; 13(11): 3864. 